\title{
Crop-specific and single-species mycorrhizal inoculation is the best approach to improve crop growth in controlled environments
}

\author{
Maarten Van Geel $^{1} \cdot$ Matthias De Beenhouwer $^{1} \cdot$ Bart Lievens $^{2} \cdot$ Olivier Honnay $^{1}$
}

Accepted: 13 May 2016/Published online: 1 June 2016

(C) INRA and Springer-Verlag France 2016

\begin{abstract}
Arbuscular mycorrhizal fungi are root symbionts that play a key role in crop growth. A systematic quantitative analysis of the response of crops to arbuscular mycorrhizal inoculation, however, remains to be done. Additionally, little is known regarding the role of mycorrhizal specificity and the diversity of the inoculum on crop growth. Therefore, we collected data from 115 inoculation studies, including 435 experiments. We then used meta-analysis to examine the effect of crop identity, arbuscular mycorrhizal fungus identity, and mycorrhizal diversity on crop biomass increase, following inoculation. Our results show that total crop biomass was on average $34.9 \%$ higher in inoculated versus non-inoculated plants. We found that specific combinations of arbuscular mycorrhizal fungus genera and host plant families were more beneficial for growth promotion as compared to other combinations. Moreover, a single-species inoculum increased crop growth response on average by $41.2 \%$ compared to a multi-species inoculum. Overall, our findings show that a broad range of crops highly benefit from the inoculation with arbuscular mycorrhizal fungi. They also strongly suggest that selecting specific arbuscular mycorrhizal taxa for specific crops is the most promising approach to enhance crop growth. There is no "onesize-fits-all" arbuscular mycorrhizal fungus. Finally, and at least in stable and controlled environments, inoculation with a single
\end{abstract}

Maarten Van Geel

maarten.vangeel@bio.kuleuven.be

1 Plant Conservation and Population Biology, Department of Biology, KU Leuven, Kasteelpark Arenberg 31, 3001 Heverlee, Belgium

2 Laboratory for Process and Bioinspirational Management (PME\&BIM), Department of Microbial and Molecular Systems (M2S), KU Leuven, Campus De Nayer, 2860 Sint-Katelijne Waver, Belgium arbuscular mycorrhizal species is more effective, compared to inoculation with a mixture of different arbuscular mycorrhizal taxa. This may be explained by fungi superior in extraradical growth, but less beneficial to the host, that outcompete the more mutualistic fungi. Therefore, it may be beneficial to maintain a high dominance of one beneficial arbuscular mycorrhizal taxon in simplified agricultural systems.

Keywords AMF $\cdot$ Biodiversity $\cdot$ Host preference $\cdot$ Host selectivity $\cdot$ Meta-analysis $\cdot$ Specificity

\section{Introduction}

Arbuscular mycorrhizal fungi (Glomeromycota) are widespread and obligate plant symbionts known to play a key role in the functioning of agricultural ecosystems and crop productivity (Verbruggen et al. 2010). These fungi establish a symbiosis with the majority of the land plants and generally provide mineral nutrients to the host plant in exchange for plantassimilated carbohydrates (Smith and Read 2008). Furthermore, they form a large network of hyphae and have a great impact on soil formation and soil aggregation (Wilson et al. 2009). Finally, arbuscular mycorrhizal fungi can provide protection of the host plant against fungal and nematode pathogens (Veresoglou and Rillig 2012). Overall, arbuscular mycorrhizal fungi have been shown to increase host plant biomass production (Hoeksema et al. 2010), although a systematic analysis on the response of crop species in particular remains to be done (Fig. 1). However, whereas the symbiosis is often seen as an unambiguous mutualism where especially the host plants often benefit from the association, arbuscular mycorrhizal fungi have also been reported to be of little benefit to the host plant and even to be parasitic by causing a net carbon cost for the host (Johnson et al. 1997; Graham and Eissenstat 1998). 


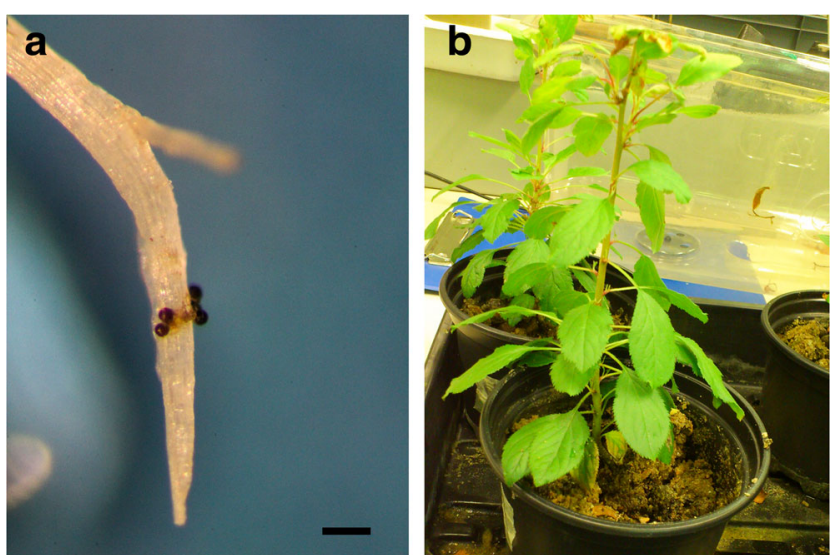

Fig. 1 An example of an inoculation experiment, related to the study of Van Geel et al. (2015), to compare the growth response of mycorrhizal to non-mycorrhizal apple seedlings. In order to establish a single-species culture, arbuscular mycorrhizal fungal spores were first isolated from the field. Next, spores with similar morphology were carefully applied to the root tips of Plantago lanceolata (a), a good host plant known to form a symbiosis with a broad variety of arbuscular mycorrhizal fungi. After 6 months of growth in the greenhouse, the cultures were used to inoculate apple seedlings (b) and to evaluate the growth response to AMF inoculation in comparison to non-mycorrhizal seedlings. Bar indicates $200 \mu \mathrm{m}$

Based on morphological characteristics of spores, 244 arbuscular mycorrhizal species have been described so far (Schüssler 2014). Direct sequencing of fungal ribosomal RNA genes from the soil on the other hand has revealed the existence of 341 virtual arbuscular mycorrhizal taxa so far (operational taxonomic units (OTUs)) (Öpik et al. 2013). Consequently, the number of known arbuscular mycorrhizal species/virtual taxa is very low, compared to the $c .200 .000$ plant species they associate with (Brundrett 2009), suggesting that arbuscular mycorrhizal specificity to the host plant is very low (Mosse 1975; McGonigle and Fitter 1990). Nevertheless, some studies found evidence that co-existing plant species harbor different arbuscular mycorrhizal communities (Vandenkoornhuyse et al. 2003; Torrecillas et al. 2012). Furthermore, specificity in the arbuscular mycorrhizal symbiosis may also occur at a higher level, such as the ecological group (Öpik et al. 2009) or family (Torrecillas et al. 2012) of the host plant.

In addition to the extent of arbuscular mycorrhizal fungi specificity, little is known regarding the role of arbuscular mycorrhizal diversity on host plant growth. In a more general context, there is now convincing evidence that higher species diversity is generally beneficial for a range of ecosystem functions (Cardinale et al. 2012). For example, a higher plant species or pollinator species richness may result in higher biomass production and crop pollination, respectively, either through the sampling effect or through the complementarity effect. The sampling effect refers to having a greater chance of including a very effective species with respect to the ecosystem functioning, whenever there is a higher species diversity (Turnbull et al. 2013). The complementarity effect refers to resource partitioning through functional complementarity, which leads to a more efficient exploitation of resources in the system (Tilman 1997). Also, arbuscular mycorrhizal taxa are known to be functionally different, for example, regarding the formation of extra-radical hyphae, colonization rates and their phosphorus foraging strategy (Hart and Reader 2002). This may result in a more efficient exploitation of soil resources in case of the presence of different arbuscular mycorrhizal taxa and a direct fitness benefit for the host plant. For example, compared to colonization by a single arbuscular mycorrhizal fungus, colonization by two arbuscular mycorrhizal fungi with different spatial abilities to acquire soil phosphorus induces a larger growth response in the host plant (Smith et al. 2000). Although van der Heijden et al. (1998) already provided insights in the relation between mycorrhizal diversity and ecosystem functioning, their results were based on microcosms and macrocosm mimicking European calcareous grasslands, and are as such difficult to transpose to crops in an agricultural context. Even though there have been many experimental studies testing the growth response of a broad range of crops to single and multiple mycorrhizal inoculations, the results obtained appear to be inconsistent. On the one hand, many studies have shown an increased growth benefit of crops to inoculation with multiple arbuscular mycorrhizal fungi compared to inoculation with a single arbuscular mycorrhizal fungus (e.g., Ortas and Ustuner 2014; Pellegrino and Bedini 2014a). On the other hand, Hart et al. (2013), for example, showed that high fungal diversity in the roots of a plant can facilitate the persistence of low-quality symbionts, resulting in a very limited growth benefit to their host. Consequently, it is still unclear to what extent mycorrhizal diversity can promote growth in the host plant.

Meta-analysis is a statistical technique used to summarize and quantify a selected set of studies (Borenstein et al. 2011). Given the large number of studies, performed with different crops and different arbuscular mycorrhizal fungi, a metaanalysis now allows to integrate their results and provide quantitative answers regarding the outcome of different arbuscular mycorrhizal taxa-host plant combinations and to what extent mycorrhizal diversity can promote crop growth. More specifically, the objectives of this study were to (i) quantify the overall growth response of crop species to arbuscular mycorrhizal inoculation, (ii) assess the importance of arbuscular mycorrhizal specificity on the growth response of crop species, and (iii) evaluate to what extent arbuscular mycorrhizal diversity can promote crop growth.

\section{Materials and methods}

\subsection{Data compilation}

Data were compiled based on articles retrieved from a Web of Knowledge search on the 15th of October 2015, using the 
search string "arbuscular mycorrhiza* AND inoculat*" (resulting in 1701 articles). Articles were then included in the meta-analysis when they included at least one experiment that met the following criteria: (i) a crop was inoculated with one or more arbuscular mycorrhizal taxa and the vegetative or generative response (root, shoot, or fruit biomass) was compared with the non-mycorrhizal crop (control) and (ii) both a measure of variance in plant response and the number of replicates were reported. Furthermore, when multiple phosphorus levels were compared within a study, we only included the "normal" treatment in our meta-analysis, and not the fertilized treatment.

From each experiment that met these criteria, we retrieved data on plant growth (root, shoot, total, and/or fruit biomass), with and without mycorrhizal inoculation. If not reported, standard deviations were calculated from sampling sizes and standard errors. When results were only reported in figures, the raw data were extracted using GetData Graph Digitizer (version 2.26; http://getdata-graph-digitizer.com). From each experiment, also crop species, arbuscular mycorrhizal fungi taxon (species names were annotated according to Schüssler and Walker (2010)) and inoculum type (single-species vs. multi-species inoculum) were recorded.

\subsection{Statistical analysis}

For each experimental comparison between inoculated and control treatments, an effect size for plant biomass response was calculated. We used total plant biomass when available or calculated it as the sum of root and shoot biomass. In the minority of cases where total plant biomass was not available or could not be calculated, we used shoot biomass as a proxy for total plant biomass. We then used the response ratio $\operatorname{Ln}(\mathrm{R})=\operatorname{Ln}\left(X_{\mathrm{AMF}} / X_{\mathrm{c}}\right)$ as the effect size, where $X_{\mathrm{AMF}}$ and $X_{\mathrm{c}}$ are the mean total biomass values for the inoculated and control treatments, respectively (Hedges et al. 1999). A positive value of $\operatorname{Ln}(\mathrm{R})$ indicates a positive effect of arbuscular mycorrhizal fungi inoculation on total plant biomass. A value of $\mathrm{Ln}(\mathrm{R})=0$ indicates that arbuscular mycorrhizal fungi inoculation had no effect. For each experimental comparison, both $\operatorname{Ln}(\mathrm{R})$ and the variance of $\operatorname{Ln}(\mathrm{R})$ were calculated using MetaWin v2.1 (Rosenberg et al. 2000). Because only a limited number of experimental comparisons between arbuscular mycorrhizal fungi inoculation and control treatments (66 out of $435,15 \%$ ) reported a measure of fruit biomass, no meaningful analysis was possible on the effect of arbuscular mycorrhizal fungi inoculation on fruit biomass.

We then used general linear models (GLMs) in SPSS 20.0 (SPSS Inc., Chicago, IL, USA) to simultaneously estimate the effects of multiple explanatory variables on total plant biomass to arbuscular mycorrhizal fungi inoculation. Two models were ran with $\mathrm{Ln}(\mathrm{R})$ as the response variable and the following fixed explanatory variables: arbuscular mycorrhizal fungi genus, crop family, arbuscular mycorrhizal fungi genus $\times$ crop family (model 1 ) and inoculum type (single-species or multi-species inoculum) (model 2). The observations with multiple AMF taxa were omitted in model 1. The Bayesian information criterion (BIC) was used to select the most parsimonious model out of a suite of reduced models compared with the full model (i.e., with the lowest BIC). In all cases, we used the full model which had the lowest BIC. The high number of crop species and arbuscular mycorrhizal taxa in our dataset did not allow to conduct a meaningful analysis at the species level. It is normal conduct in meta-analysis to give higher weight to more accurate effect sizes (Borenstein et al. 2011). Therefore, a weight factor (1/variance of the effect size) was included in all models.

When a study reported more than one experiment, these experiments were included as separate data records. To test whether this approach may have led to an overrepresentation of the effect of studies that included a high number of experiments, we randomly chose one observation from each study and conducted the same analysis (He and Dijkstra 2014). The mean effect sizes that were calculated this way were similar to the effect sizes based on the whole dataset, suggesting that overrepresentation did not occur (He and Dijkstra 2014). Finally, the presence of a publication bias was tested using scatter plots of effect size versus their variance and the sample size of each experiment. No patterns indicative of publication bias could be discovered (data not shown).

\section{Results and discussion}

In total, 115 publications met our criteria, resulting in 435 experimental comparisons between arbuscular mycorrhizal fungi inoculation and control treatments. Both models showed an overall positive response of total biomass to inoculation with arbuscular mycorrhizal fungi. Our first model estimated the overall response ratio of total biomass at $0.290(95 \% \mathrm{CI}$ 0.133 to 0.448 ), the second model at 0.307 (95\% CI 0.248 to 0.366). Although our first model found no overall significant main effect of arbuscular mycorrhizal fungi genus, the $95 \%$ confidence intervals of the mean effect sizes for the genera Glomus and Funneliformis did not include zero, indicating a positive growth response to inoculation with arbuscular mycorrhizal fungi (Fig. 2a). Similarly, although there was no main effect of crop family, the crop families Cucurbitaceae and Poaceae showed the strongest positive response to arbuscular mycorrhizal fungi inoculation and the $95 \%$ confidence intervals of the effect sizes did not include zero (Fig. 2a). Whereas no main effects of arbuscular mycorrhizal fungi genus and crop family on total plant biomass were found, the significant interaction between arbuscular mycorrhizal fungi genus and crop family indicated that the effect of arbuscular mycorrhizal fungi genus is dependent on crop family (Table 1) and that the main effects discussed above have to 
Fig. 2 The estimated marginal means $( \pm 95 \%$ confidence intervals) of the general linear model analyses relating the effect size for the total plant biomass to the identity of the inoculated arbuscular mycorrhizal fungi $(A M F)$ and the identity of the crop (a) and to the inoculum type (b). The effect of arbuscular mycorrhizal inoculation was considered statistically significant if the $95 \%$ confidence intervals of the mean effect size did not overlap with zero. A positive response ratio $(\operatorname{Ln}(\mathrm{R}))$ indicates a positive effect of arbuscular mycorrhizal inoculation on total plant biomass. $P$ values reported are those obtained in both general linear model analyses (Table 1). The number of observations in each group is shown in parentheses. Groups with less than three observations are not shown. Arbuscular mycorrhizal fungi is abbreviated as $A M F$

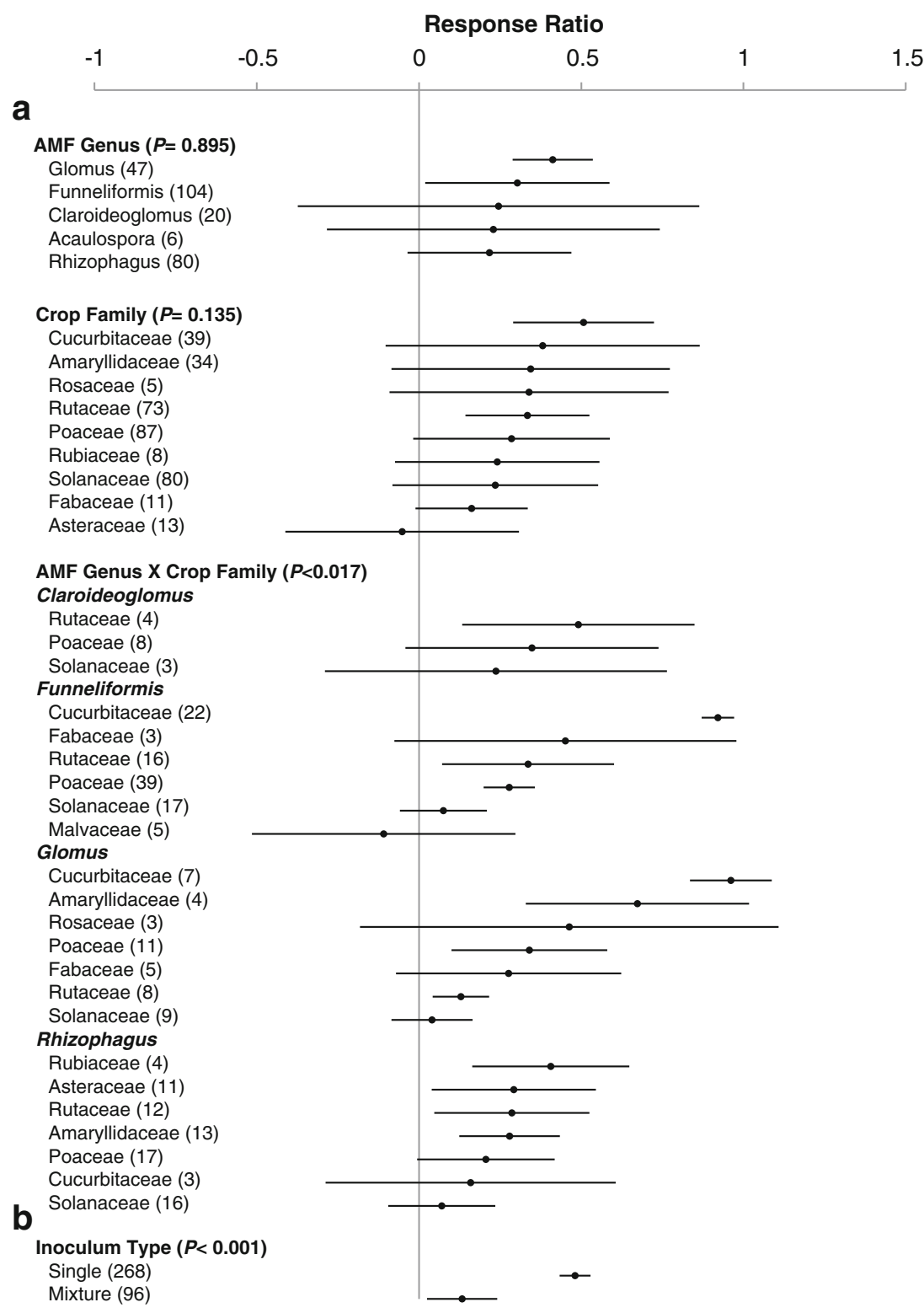

.5
Table 1 Results from the general linear model analysis relating the effect size for total plant biomass to the genus of the inoculated arbuscular mycorrhizal fungi (AMF) and the crop family (model 1, and to the inoculum type (model 2)

\begin{tabular}{llll}
\hline Explanatory variables & df & $F$ & $P$ \\
\hline Model 1 & 1 & 3.815 & 0.052 \\
Intercept & 9 & 0.469 & 0.895 \\
AMF genus & 13 & 1.451 & 0.135 \\
Crop family & 29 & 1.690 & 0.017 \\
AMF genus $\times$ crop family & & & \\
Model 2 & 1 & 104.265 & $<0.001$ \\
Intercept & 1 & 33.545 & $<0.001$ \\
Inoculum type & & &
\end{tabular}

be interpreted in this context. Especially, the symbiosis between arbuscular mycorrhizal fungi from the genera Funneliformis or Glomus and crops from the Cucurbitaceae and arbuscular mycorrhizal fungi from the genus Rhizophagus and crops from the Rubiaceae resulted in a strong plant growth response (Fig. 2a). On the contrary, the symbiosis between arbuscular mycorrhizal fungi from the genera Funneliformis or Glomus and crop plants from the family Solanaceae did not result in a positive growth response (95\% confidence intervals did overlap with zero). Also, the symbiosis between arbuscular mycorrhizal fungi from the genera Rhizophagus and crop plants from the family Cucurbitaceae did not result in a positive growth response.

Whereas arbuscular mycorrhizal fungi were originally considered to be non-specific (Mosse 1975; McGonigle and Fitter 1990), more recent studies demonstrated an affinity of certain 
arbuscular mycorrhizal taxa for specific plant species or cultivars (e.g., Vestberg 1992; Vandenkoornhuyse et al. 2003; Torrecillas et al. 2012). Our results demonstrate that specific combinations of arbuscular mycorrhizal fungi genera and host plant families are more efficient for growth promotion of crops as compared to others. We showed that arbuscular mycorrhizal specificity may also translate into differing growth responses of crops. Insufficient available data in the literature did not allow us to systematically evaluate specificity at the species level. Nevertheless, when the most frequently occurring arbuscular mycorrhizal species in our dataset was considered, Funneliformis mosseae $(n=104)$, still large differences in plant growth were found between crop species $(P<0.001)$. Cucumber, for example, showed a significantly higher growth response compared to cotton, maize, tobacco, or tomato when inoculated with $F$. mosseae, suggesting a trend of arbuscular mycorrhizal specificity at the species level as well.

Our second model resulted in a significant effect of inoculum type on the effect size for total plant biomass (Table 1). Although both inoculum types (single-species vs. multispecies inoculum) resulted in a positive growth response, the single-species inoculum had a mean growth response of 0.481 (95\% CI 0.433 to 0.528 ), compared to only 0.133 (95\% CI 0.025 to 0.241 ) for the multi-species inoculum (Fig. 2b). These results were somewhat counter-intuitive as it was expected that sampling and complementarity effects would result in higher plant growth following inoculation with multiple arbuscular mycorrhizal taxa. On the contrary, our analysis indicates that crop plants that could have been colonized by multiple arbuscular mycorrhizal taxa perform less, compared to crop plants colonized by a single arbuscular mycorrhizal taxon. These findings resemble those of Veresoglou and Rillig (2012) who found that a host plant colonized by multiple arbuscular mycorrhizal taxa suppresses fungal pathogens less efficiently than when colonized by a single arbuscular mycorrhizal species.

van der Heijden et al. (1998) found that increasing the arbuscular mycorrhizal diversity in artificial mesocosms led to increased plant productivity. The proposed mechanism for this effect, however, was based on variable plant growth responses of different arbuscular mycorrhiza-host plant combinations. In our model 1, we also demonstrated variable growth responses of different arbuscular mycorrhiza-host plant combinations, and therefore, our results, based on growth responses of individual crops, are consistent with van der Heijden et al. (1998). Additionally, the lower effect on the growth response of crops of the multi-species compared to the single-species inocula can be explained by the nature of the studies included in our meta-analysis, which were mainly short-term inoculation studies performed in controlled artificial environments. Indeed, a higher magnitude and stability of ecosystem functions associated with diversity are likely most evident under changing and/or heterogeneous conditions that crops experience in the field. In plant communities, the stabilizing effect of diversity on ecosystem properties can be explained by temporal complementarity between species (Loreau and de Mazancourt 2013). In stable controlled experiments, however, temporal complementarity can hardly play any role.

In these stable controlled environments, the lower effect of arbuscular mycorrhizal diversity on individual host plants may be explained by competition among arbuscular mycorrhizal taxa, with arbuscular mycorrhizal fungi superior in extraradical growth, but less beneficial to the host plant, outcompeting more mutualistic arbuscular mycorrhizal fungi (Werner and Kiers 2015a). Hart et al. (2013), moreover, have shown that diverse arbuscular mycorrhizal communities on Plantago lanceolata can support the persistence of a less-beneficial symbiont. Complementary, also priority, effects, i.e., the impact of species arrival on subsequent community development, may negatively affect host plant growth following inoculation with different arbuscular mycorrhizal taxa. Werner and Kiers (2015) argued against space limitation as the mechanism allowing priority effects to emerge in the arbuscular mycorrhizal fungal system. Instead, their data supported an active downregulation of specific mycorrhizal partners by the host. Such systemic suppression of arbuscular mycorrhizal fungi by the host has also been observed in split-root experiments in which an established arbuscular mycorrhizal symbiosis suppressed subsequent colonization by different arbuscular mycorrhizal species in the second side of the split-root system (Vierheilig et al. 2000). Although arbuscular mycorrhizal species were inoculated simultaneously in all studies in our dataset, certain taxa may be more efficient colonizers and may consequently inhibit colonization by arbuscular mycorrhizal fungi that are more beneficial to the host plant.

As said, our meta-analysis is based on results from shortterm inoculation studies performed in controlled artificial environments. Plants are grown separately in a soil that has been kept moist, autoclaved, mixed with sand, and placed in plastic pots. The soil is inoculated with a single arbuscular mycorrhizal fungus that may not naturally interact with the host. Also, the host is not exposed to naturally occurring arbuscular mycorrhiza, pathogens, or plants. Therefore, caution is required before extrapolating our results to natural settings with complex community interactions and changing environmental conditions (Lekberg and Koide 2014).

We used a multi-factor model with two categorical predictors to assess the role of different arbuscular mycorrhizal taxa and crop families on the response of crops to mycorrhizal inoculation. Because data availability was dependent on what was found in the literature, some combinations of levels of predictor variable occurred more than others, generating incomplete orthogonality between the explanatory variables of our model 1. In such an unbalanced design, the fitted parameter values may be different from the observed parameter values. Although some small differences between fitted and 
observed parameter values occurred in our dataset, the data from the observed parameter values generally supported the same conclusions.

\section{Conclusion}

Our findings may have important implications regarding applications of arbuscular mycorrhizal fungi in agriculture. They could serve as a general guideline towards selecting arbuscular mycorrhizal strains to be used as inocula in agriculture and potentially guide agricultural management practices. On the one hand, they confirm that a broad range of crop plants can benefit from the inoculation with arbuscular mycorrhizal fungi and that there is a high potential for additional growth. On the other hand, our results suggest that specific arbuscular mycorrhizal taxa-host plant combinations enhance the growth of a crop and that, at least in stable and controlled environments, inoculation with a single arbuscular mycorrhizal species may be more beneficial to crop species, compared to inoculation with a mixture of different arbuscular mycorrhizal taxa. In other words, our results indicate that there is no "one-size-fits-all" arbuscular mycorrhizal fungus, and suggest that there may be potential benefits in maintaining high dominance of one very beneficial arbuscular mycorrhizal taxon. Yet, caution is required when extrapolating our results to natural field conditions with more complex community interactions and variable environmental conditions. Further research should focus on finding the particular arbuscular mycorrhizal taxon-host plant combination that will maximize growth response, both ex situ and under field conditions. Finally, we encourage researchers conducting arbuscular mycorrhizal inoculation experiments to report also on the marketable part of the plant and not only on the root and shoot biomass.

Acknowledgments This study was funded by the project IWT-LA 110775 of the Institute for the Promotion of Innovation by Science and Technology in Flanders. Also, we would like to thank Dr. Tobias Ceulemans for the constructive comments.

\section{References}

Borenstein M, Hedges LV, Higgens JPT, Rothstein HR (2011) Introduction to meta-analysis. Wiley, Chichester

Brundrett MC (2009) Mycorrhizal associations and other means of nutrition of vascular plants: understanding the global diversity of host plants by resolving conflicting information and developing reliable means of diagnosis. Plant Soil 320:37-77. doi:10.1007/s11104-0089877-9

Cardinale BJ, Duffy JE, Gonzalez A, Hooper DU, Perrings C, Venail P, Narwani A, Mace GM, Tilman D, Wardle DA, Kinzig AP, Daily GC, Loreau M, Grace JB, Larigauderie A, Srivastava DS, Naeem S (2012) Biodiversity loss and its impact on humanity. Nature 486:59 67. doi:10.1038/nature11148
Graham JH, Eissenstat DM (1998) Field evidence for the carbon cost of citrus mycorrhizas. New Phytol 140:103-110. doi:10.1046/j.14698137.1998.00251.x

Hart M, Reader R (2002) Taxonomic basis for variation in the colonization strategy of arbuscular mycorrhizal fungi. New Phytol 153:335344. doi:10.1046/j.0028-646X.2001.00312.x

Hart MM, Forsythe J, Oshowski B, Bücking H, Jansa J (2013) Hiding in a crowd - does diversity facilitate persistence of a low-quality fungal partner in the mycorrhizal symbiosis? Symbiosis 59:47-56. doi:10. 1007/s13199-012-0197-8

He M, Dijkstra FA (2014) Drought effect on plant nitrogen and phosphorus: a meta-analysis. New Phytol 204:924-931. doi:10.1111/nph. 12952

Hedges LV, Gurevitch J, Curtis PS (1999) The meta-analysis of response ratios in experimental ecology. Ecology 80:1150-1156. doi:10. 2307/177062

Hoeksema JD, Chaudhary VB, Gehring CA, Johnson NC, Karst J, Koide RT, Pringle A, Zabinski C, Bever JD, Moore JC, Wilson GW, Klironomos JN, Umbanhowar J (2010) A meta-analysis of contextdependency in plant response to inoculation with mycorrhizal fungi. Ecol Lett 13:394-407. doi:10.1111/j.1461-0248.2009.01430.x

Johnson NC, Graham JH, Smith FA (1997) Functioning of mycorrhizal associations along the mutualism parasitism continuum. New Phytol 135:575-585. doi:10.1046/j.1469-8137.1997.00729.x

Lekberg Y, Koide RT (2014) Integrating physiological, community, and evolutionary perspectives on the arbuscular mycorrhizal symbiosis. Botany 92:241-251. doi:10.1139/cjb-2013-0182

Loreau M, de Mazancourt C (2013) Biodiversity and ecosystem stability: a synthesis of underlying mechanisms. Ecol Lett 16:106-115. doi: 10.1111/ele. 12073

McGonigle TP, Fitter AH (1990) Ecological specificity of vesiculararbuscular mycorrhizal associations. Mycol Res 94:120-122. doi: 10.1016/S0953-7562(09)81272-0

Mosse B (1975) Specificity in VA mycorrhizas. In: Endomycorrhizas. Academic Press, London, UK, pp 469-484

Öpik M, Metsis M, Daniell TJ, Zobel M, Moora M (2009) Large-scale parallel 454 sequencing reveals host ecological group specificity of arbuscular mycorrhizal fungi in a boreonemoral forest. New Phytol 184:424-437. doi:10.1111/j.1469-8137.2009.02920.x

Öpik M, Zobel M, Cantero J, Davison J, Facelli J, Hiiesalu I, Jairus T, Kalwij J, Koorem K, Leal M, Liira J, Metsis M, Neshataeva V, Paal J, Phosri C, Põlme S, Reier U, Saks U, Schimann H, Thiéry O, Vasar M, Moora M (2013) Global sampling of plant roots expands the described molecular diversity of arbuscular mycorrhizal fungi. Mycorrhiza 23:411-430. doi:10.1007/s00572-013-0482-2

Ortas I, Ustuner O (2014) The effects of single species, dual species and indigenous mycorrhiza inoculation on citrus growth and nutrient uptake. Eur J Soil Biol 63:64-69. doi:10.1016/j.ejsobi.2014.05.007

Pellegrino E, Bedini S (2014a) Enhancing ecosystem services in sustainable agriculture: biofertilization and biofortification of chickpea (Cicer arietinum L.) by arbuscular mycorrhizal fungi. Soil Biol Biochemistry 68:429-439. doi:10.1016/j.soilbio.2013.09.030

Rosenberg MS, Adams DC, Gurevitch J (2000) MetaWin: statistical software for meta-analysis. Version 2. Sinauer Associates, Massachusetts

Schüssler A (2014) Glomeromycota: species list. URL: schuessler.userweb.mwn.de/amphylo

Schüssler A, Walker C (2010) The Glomeromycota. A species list with new families and new genera Published in libraries at The Royal Botanic Garden Edinburgh, The Royal Botanic Garden Kew, Botanische Staatssammlung Munich, and Oregon State University

Smith SE, Read DJ (2008) Mycorrhizal symbiosis. Academic, Cambridge

Smith FA, Jakobsen I, Smith SE (2000) Spatial differences in acquisition of soil phosphate between two arbuscular mycorrhizal fungi in symbiosis with Medicago truncatula. New Phytol 147:357-366. doi:10. 1046/j.1469-8137.2000.00695.x 
Tilman D (1997) The influence of functional diversity and composition on ecosystem processes. Science 277. doi: 10.1126/science.277. 5330.1300

Torrecillas E, Alguacil MM, Roldan A (2012) Host preferences of arbuscular mycorrhizal fungi colonizing annual herbaceous plant species in semiarid Mediterranean prairies. Appl Environ Microbiol 78:6180-6186. doi:10.1128/AEM.01287-12

Turnbull LA, Levine JM, Loreau M, Hector A (2013) Coexistence, niches and biodiversity effects on ecosystem functioning. Ecol Lett 16: 116-127. doi:10.1111/ele.12056

van der Heijden MGA, Klironomos JN, Ursic M, Moutoglis P, StreitwolfEngel R, Boller T, Wiemken A, Sanders IR (1998) Mycorrhizal fungal diversity determines plant biodiversity, ecosystem variability and productivity. Nature 396:69-72. doi:10.1038/23932

Van Geel M, Ceustermans A, Van Hemelrijck W, Lievens B, Honnay O (2015) Decrease in diversity and changes in community composition of arbuscular mycorrhizal fungi in roots of apple trees with increasing orchard management intensity across a regional scale. Mol Ecol 24:941-952. doi:10.1111/mec.13079

Vandenkoornhuyse P, Ridgway KP, Watson IJ, Fitter AH, Young JP (2003) Co-existing grass species have distinctive arbuscular mycorrhizal communities. Mol Ecol 12:3085-3095. doi:10.1046/j.1365294X.2003.01967.X

Verbruggen E, Röling W, Gamper H, Kowalchuk G, Verhoef H, van der Heijden M (2010) Positive effects of organic farming on belowground mutualists: large-scale comparison of mycorrhizal fungal communities in agricultural soils. New Phytol 186:968-979. doi: 10.1111/j.1469-8137.2010.03230.x

Veresoglou S, Rillig M (2012) Suppression of fungal and nematode plant pathogens through arbuscular mycorrhizal fungi. Biol Lett 8:214 217. doi:10.1098/rsbl.2011.0874

Vestberg M (1992) The effect of vesicular-arbuscular mycorrhizal inoculation on the growth and root colonization of ten strawberry cultivars. J Agric Sci 1:527-535

Vierheilig H, Garcia-Garrido JM, Wyss U, Piché Y (2000) Systemic suppression of mycorrhizal colonization of barley roots already colonized by AM fungi. Soil Biol Biochem 32:589-595. doi:10.1016/ S0038-0717(99)00155-8

Werner GD, Kiers ET (2015a) Order of arrival structures arbuscular mycorrhizal colonization of plants. New Phytol 205:1515-1524. doi: 10.1111/nph.13092

Werner GD, Kiers ET (2015b) Partner selection in the mycorrhizal mutualism. New Phytol 205:1437-1442. doi:10.1111/nph.13113

Wilson G, Rice C, Rillig M, Springer A, Hartnett D (2009) Soil aggregation and carbon sequestration are tightly correlated with the abundance of arbuscular mycorrhizal fungi: results from long-term field experiments. Ecol Lett 12:452-461. doi:10.1111/j.1461-0248.2009. 01303.x

\section{References of the meta-analysis}

Abdel-fattah GM, Asrar AA, Al-Amri SM, Abdel-Salam EM (2014) Influence of arbuscular mycorrhiza and phosphorus fertilization on the gas exchange, growth and phosphatase activity of soybean (Glycine max L) plants. Photosynthetica 52:581-588. doi:10.1007/ s11099-014-0067-0

Aroca R, Alguacil del Mar M, Vernieri P, Ruiz-Lozano JM (2008) Plant responses to drought stress and exogenous $\mathrm{ABA}$ application are modulated differently by mycoorhization in tomato and an ABAdeficient mutant (Sitiens). Microbiol Ecol 56:704-719. doi:10.1007/ s00248-008-9390-y
Aroca R, Ruiz-Lozano JM, Zamarreno AM, Paz JA, Garcia-Mina JM, Pozo MJ, Lopez-Raez JA (2012) Arbuscular mycorrhizal symbiosis influences strigolactone production under salinity and alleviates salt stress in lettuce plants. J Plant Physiol 170:47-55. doi:10.1016/j. jplph.2012.08.020

Azcon R, Ocampo J (1981) Factors affecting the vesicular-arbuscular infection and mycorrhizal dependency of thirteen wheat cultivars. New Phytol 87:677-685. doi:10.1111/j.1469-8137.1981.tb01702.x

Basak H, Demir K, Kasim R, Okay FY (2011) The effect of endomycorrhiza (VAM) treatment on growth of tomato seedling grown under saline conditions. Afr J Agric Res 6:2532-2538. doi:10.5897/ AJAR11.033

Berta G, Copetta A, Gamalero E, Bona E, Cesaro P, Scarafoni A, D'agostino G (2014) Maize development and grain quality are differentially affected by mycorrhizal fungi and a growth-promoting pseudomonad in the field. Mycorrhiza 24:161-170. doi:10.1007/ s00572-013-0523-x

Bethlenfalvay GJ, Schreiner RP, Mihara KL, McDaniel H (1996) Mycorrhizae, biocides, and biocontrol Mycorrhizal fungi enhance weed control and crop growth in a soybean-cocklebur association treated with the herbicide bentazon. Appl Soil Ecol 3:205-214. doi: 10.1016/0929-1393(96)00093-5

Bethlenfalvay GJ, Schreiner RP, Mihara KL (1997) Mycorrhizal fungi effects on nutrient composition and yield of soybean seeds. J Plant Nut 20:581-591. doi:10.1080/01904169709365276

Bettoni MM, Mogor AF, Pauletti V, Goicoechea N (2014) Growth and metabolism of onion seedlings as affected by the application of humic substances, mycorrhizal inoculation and elevated $\mathrm{CO}_{2}$. Sci Hortic 180:235-277. doi:10.1016/j.scienta.2014.10.037

Borowicz AV (2010) The impact of arbuscular mycorrhizal fungi on strawberry tolerance to root damage and drought stress. Pedobiologia 53:265-270. doi:10.1016/j.pedobi.2010.01.001

Boyacioglu TU, Uyanoz R (2014) Effects of Mycorrhizal fungi on tolerance capability of corn grown under salt stress condition. J Plant Nut 37:107-122. doi:10.1080/01904167.2013.849732

Campos-Soriano L, Garcia-Garrido JM, San Segundo B (2010) Activation of basal defense mechanisms of rice plants by Glomus intraradices does not affect the arbuscular mycorrhizal symbiosis. New Phytol 188:597-614. doi:10.1111/j.1469-8137.2010.03386.x

Cantrell IC, Linderman RG (2001) Preinoculation of lettuce and onion with VA mycorrhizal fungi reduces deleterious effects of soil salinity. Plant Soil 233:269-281. doi:10.1023/A:1010564013601

Cardoso IM, Boddington CL, Janssen BH, Oenema O, Kuyper TW (2004) Double pot and double compartment: integrating two approaches to study nutrient uptake by arbuscular mycorrhizal fungi. Plant Soil 260:301-310. doi:10.1023/B:PLSO.0000030180.95607. ob

Cavagnaro TR, Martin AW (2011) Arbuscular mycorrhizas in southeastern Australian processing tomato farm soils. Plant Soil 340:327336. doi:10.1007/s11104-010-0603-Z

Cavagnaro TR, Jackson LE, Six J, Ferris H, Goyal S, Asami D, Scow KM (2006) Arbuscular mycorrhizas, microbial communities, nutrient availability, and soil aggregates in organic tomato production. Plant Soil 282:209-225. doi:10.1007/s11104-005-5847-7

Cavagnaro TR, Sokolow SK, Jackson L (2007) Mycorrhizal effects on growth and nutrition of tomato under elevated atmospheric carbon dioxide. Func Plant Biol 34:730-736. doi:10.1071/FP06340

Cavagnaro TR, Langley AJ, Jackson LE, Smukler SM, Koch GW (2008) Growth, nutrition, and soil respiration of a mycorrhiza-defective tomato mutant and its mycorrhizal wild-type progenitor. Func Plant Biol 35:228-235. doi:10.1071/FP07281

Cavagnaro TR, Barrios-Masias FH, Jackson LE (2012) Arbuscular mycorrhizas and their role in plant growth, nitrogen interception and soil gas efflux in an organic production system. Plant Soil 353:181194. doi:10.1007/s11104-011-1021-6 
Ceasar SA, Hodge A, Baker A, Baldwin SA (2014) Phosphate concentration and arbuscular mycorrhizal colonisation influence the growth, yield and expression of twelve PHT1 family phosphate transporters in foxtail millet (Setaria italica). Plos One 9:e108459. doi:10.1371/journal.pone.0108459

Ceballos I, Ruiz M, Fernandez C, Pena R, Rodriguez A, Sanders IR (2013) The in vitro mass-produced model mycorrhizal fungus, Rhizophagus irregularis, significantly increases yields of the globally important food security crop cassava. Plose One 8:e70633. doi: 10.1371/journal.pone.0070633

Chen X, Li H, Chan WF, Wu C, Wu F, Wu S, Wong MH (2012) Arsenite transporters expression in rice (Oryza sativa $\mathrm{L}$ ) associated with arbuscular mycorrhizal fungi (AMF) colonization under different levels of arsenite stress. Chemosphere 89:1248-1254. doi:10.1016/ j.chemosphere.2012.07.054

Chen Y, Hu C, Xiao J (2014) Effects of arbuscular mycorrhizal inoculation on the growth, zinc distribution and photosynthesis of two citrus cultivars grown in low-zinc soil. Trees 28:1427-1436. doi:10.1007/ s00468-014-1046-6

Cozzolino V, Pigna M, Meo VD, Caporale AG, Violante A (2010) Effects of arbuscular mycorrhizal inoculation and phosphorus supply on the growth of Lactuca sativa L and arsenic and phosphorus availability in an arsenic polluted soil under non-sterile conditions. Appl Soil Ecol 45:262-268. doi:10.1016/j.apsoil.2010.05.001

Dabrowska G, Christel B, Trejgell A, Hrynkiewicz K (2014) Impact of arbuscular mycorrhizal fungi on the growth and expression of gene encoding stress protein- metallothionein BnMT2 in the non-host crop Brassica napus L. J Plant Nut Soil Sci 177:459-467. doi:10. 1002/jpln.201300115

Davies FT, Calderon CM, Huaman Z (2005) Influence of arbuscular mycorrhizae indigenous to Peru and a flavonoid on growth, yield, and leaf elemental concentration of 'Yungay' potatoes. Hortscience 40:381-385

Dickson S, Smith SE, Smith FA (1999) Characterization of two arbuscular mycorrhizal fungi in symbiosis with Allium porrum: colonization, plant growth and phosphate uptake. New Phytol 144: 163-172. doi:10.1046/j.1469-8137.1999.00493.x

Dzafic E, Pongrac P, Likar M, Regvar M, Vogel-mikus K (2013) The arbuscular mycorrhizal fungus Glomus mosseae alleviates autotoxic effects in maize (Zea mays L). Eur J Soil Biol 58:59-65. doi:10. 1007/s11356-013-2360-z

Estrada B, Aroca R, Barea JM, Ruiz-Lozano JM (2013) Native arbuscular mycorrhizal fungi isolated from a saline habitat improved maize antioxidant systems and plant tolerance to salinity. Plant Sci 201: 42-51. doi:10.1016/j.plantsci.2012.11.009

Facelli E, Smith SE, Facelli JM, Christophersen HM, Smith FA (2010) Underground friends or enemies: model plants help to unravel direct and indirect effects of arbuscular mycorrhizal fungi on plant competition. New Phytol 185:1050-1061. doi:10.1111/j.1469-8137. 2009.03162.x

Fan Y, Luan Y, An L, Yu K (2008) Arbuscular mycorrhizae formed by Penicillium pinophilum improve the growth, nutrient uptake and photosynthesis of strawberry with two inoculum-types. Biotech Lett 30:1489-1494. doi:10.1007/s10529-008-9691-8

Franson RL, Hamel C, Smith DL, Bethlenfalvay GJ (1994) Belowground interactions between a seedling soybean and preestablished soybean plant with and without mycorrhizal fungi, plant biomass, root growth, and mycorrhizal colonization. Agric Ecosyst Environ 49:31-138. doi:10.1016/0167-8809(94)90003-5

Fusconi A, Lingua G, Trotta A, Berta G (2005) Effects of arbuscular mycorrhizal colonization and phosphorus application on nuclear ploidy in Allium porrum plants. Mycorrhiza 15:313-321. doi:10. 1007/s00572-004-0338-x

Gabriel-Neumann E, Neumann G, Leggewie G, George E (2011) Constitutive overexpression of the sucrose transporter SoSUT1 in potato plants increases arbuscular mycorrhiza fungal root colonization under high, but not under low, soil phosphorus availability. J Plant Physiol 168:911-919. doi:10.1016/j.jplph.2010.11. 026

Gamalero E, Berta G, Massa N, Glick BR, Lingua G (2008) Synergistic interactions between the ACC deaminase-producing bacterium Pseudomonas putida UW4 and the AM fungus Gigaspora rosea positively affect cucumber plant growth. FEMS Microbiol Ecol 64:459-467. doi:10.1111/j.1574-6941.2008.00485.x

Geil RD, Guinel FC (2002) Effects of elevated substrate-ethylene on colonization of leek (Allium porrum) by the arbuscular mycorrhizal fungus Glomus aggregatum. Can J Bot 80:114-119. doi:10.1139/ b01-135

Guo W, Zhao R, Zhao W, Fu R, Guo J, Bi N, Zhang J (2013) Effects of arbuscular mycorrhizal fungi on maize (Zea mays L) and sorghum (Sorghum bicolor L Moench) grown in rare earth elements of mine tailings. Appl Soil Ecol 72:85-92. doi:10.1016/j.apsoil.2013.06.001

Herdler S, Kreuzer K, Scheu S, Bonkowski M (2008) Interactions between arbuscular mycorrhizal fungi (Glomus intraradices, Glomeromycota) and amoebae (Acanthamoeba castellanii, Protozoa) in the rhizosphere of rice (Oryza sativa). Soil Biol Biochem 40:660-668. doi:10.1016/j.soilbio.2007.09.026

Hua J, Lin X, Yin R, Jiang Q, Shao Y (2009) Effects of arbuscular mycorrhizal fungi inoculation on arsenic accumulation by tobacco (Nicotiana tabacum L). J Environ Sci 21:2214-1220. doi:10.1016/ S1001-0742(08)62406-7

Ilbas AI, Sahin S (2005) Glomus fasciculatum inoculation improves soybean production. Soil Plant Sci 55:287-292. doi:10.1080/ 09064710500218761

Jackson LE, Miller D, Smith SE (2002) Arbuscular mycorrhizal colonization and growth of wild and cultivated lettuce in response to nitrogen and phosphorus. Sci Hortic 94:205-218. doi:10.1016/S03044238(01)00341-7

Jahromi F, Aroca R, Porcel R, Ruiz-Lozano JM (2007) Influence of salinity on the in vitro development of glomus interaradices and on the in vivo physiological and molecular responses of mycorrhizal lettuce plants. Microb Ecol 55:45-53. doi:10.1007/s00248-0079249-7

Jamal A, Ayub N, Usman M, Khan A (2002) Arbuscular mycorrhizal fungi enhance zinc and nickel uptake from contaminated soil by soybean and lentil. Int J Phytoremediat 4:205-221. doi:10.1080/ 15226510208500083

Janouskova M, Vosatka M, Rossi L, Lugon-Moulin N (2007) Effects of arbuscular mycorrhizal inoculation on cadmium accumulation by different tobacco (Nicotiana tabacum L) types. Appl Soil Ecol 35: 502-510. doi:10.1016/j.apsoil.2006.10.002

Kahiluoto H, Vestberg M (1998) The effect of arbuscular mycorrhiza on biomass production and phosphorus uptake from sparingly soluble sources by leek (Allium porrum L) in Finnish field soils. Bio Agri Hort 16:65-85. doi:10.1080/01448765.1998.9755219

Karaca H (2014) Effects of elemental sulfur and mycorrhizae on the yield of wheat in different soils. J Plant Nut 37:1-15. doi:10.1080/ 01904167.2013.789109

Karasawa T, Takebe M, Kasahara Y (2000) Arbuscular mycorrhizal (AM) effects on maize growth and AM colonization of roots under various soil moisture conditions. Soil Sc Plant Nut 46:61-67. doi: 10.1080/00380768.2000.10408762

Karasawa T, Kasahara Y, Takebe M (2002) Differences in growth responses of maize to preceding cropping caused by fluctuation in the population of indigenous arbuscular mycorrhizal fungi. Soil Biol Biochem 34:851-857. doi:10.1016/S0038-0717(02)00017-2

Ker K, Charest C (2010) Nickel remediation by AM-colonized sunflower. Mycorrhiza 20:399-406. doi:10.1007/s00572-009-0293-7

Kyrizopoulos A, Orfanoudakis M, Abraham E, Parissi Z, Serafidou N (2014) Effects of arbuscular mycorrhiza fungi on growth characteristics of Dactylis glomerata L under drought stress conditions. Not Bot Horti Agrobo 42:132-137 
Larsen J, Yohalem D (2004) Interactions between mycorrhiza and powdery mildew of cucumber. Mycol Prog 3:123-128. doi:10.1007/ S11557-006-0082-Z

Larsen J, Cornejo P, Barea JM (2009) Interactions between the arbuscular mycorrhizal fungus Glomus intraradices and the plant growth promoting rhizobacteria Paenibacillus polymyxa and $\mathrm{P}$ macerans in the mycorrhizosphere of Cucumis sativus. Soil Biol Biochem 41:286292. doi:10.1016/j.soilbio.2008.10.029

Latef AAHA, Chaoxin H (2011) Arbuscular mycorrhizal influence on growth, photosynthetic pigments, osmotic adjustment and oxidative stress in tomat plants subjected to low temperature stress. Acta Physiol Plant 33:1217-1225

Lax P, Becerra AG, Soteras F, Cabello M, Doucet ME (2011) Effect of the arbuscular mycorrhizal fungus Glomus intraradices on the false root-knot nematode Nacobbus aberrans in tomato plants. Biol Fert Soils 47:591-597. doi:10.1007/s00374-010-0514-4

Lazcano C, Barrios-Masias F, Jackson L (2014) Arbuscular mycorrhizal effects on plant water relations and soil greenhouse gas emissions under changing moisture regimes. Soil Biol Biochem 74:184-192. doi:10.1016/j.soilbio.2014.03.010

Lee YJ, George E (2005) Contribution of mycorrhizal hyphae to the uptake of metal cations by cucumber plants at two levels of phosphorus supply. Plant Soil 278:361-370. doi:10.1007/s11104-005-0373-1

Lermen C, Mohr F, Alberton O (2015) Growth of Cymbopogon citratus inoculated with mycorrhizal fungiunder different levels of lead. Sci Hortic 186:239-246. doi:10.1016/j.scienta.2015.02.029

Li H, Li X, Dou Z, Zhang J, Wang C (2012) Earthworm (Aporrectodea trapezoides)-mycorrhiza (Glomus intraradices) interaction and nitrogen and phosphorus uptake by maize. Biol Fert Soils 45:75-85. doi:10.1007/s00374-011-0610-0

Liang C, Li T, Xiao Y, Liu M, Zhang H0, Zhao W (2009) Effects of inoculation with arbuscular mycorrhizal fungi on maize grown in multi-metal contaminated soils. Int J Phytoremediat 11:692-703. doi:10.1080/15226510902787310

Linderman RG, Davis EA (2004) Evaluation of commercial inorganic and organic fertilizer effect on arbusuclar mycorrhizae fomred by Glomus intraradices. Biotechnology 14:196-203

Liu H, Wang C, Li X, Christie P, Dou Z, Zhang J, Xiang D (2013) Impact of the earthworm Aporrectodea trapezoides and the arbuscular mycorrhizal fungus Glomus intraradices on $15 \mathrm{~N}$ uptake by maize from wheat straw. Biol Fert Soils 49:263-271. doi:10.1007/s00374-0120716-z

Louissane L, Jolicoeur M, St-Arnaud M (2008) Mycorrhizal colonization with Glomus intraradices and development stage of transformed tomato roots significantly modify the chemotactic response of zoospores of the pathogen Phytophthora nicotianae. Soil Biol Biochem 40:2217-2224. doi:10.1016/j.soilbio.2008.04.013

Malcova R, Vosatka M, Gryndler M (2003) Effects of inoculation with Glomus intraradices on lead uptake by Zea mays L and Agrostis capillaris. Appl Soil Ecol 23:55-67. doi:10.1016/S0929-1393(02) 00160-9

Manjarrez M, Chrisophersen HM, Smith SE, Smith FA (2010) Cortical colonisation is not an absolute requirement for phosphorus transfer to plants in arbuscular mycorrhizas formed by Scutellospora calospora in a tomato mutant: evidence from physiology and gene expression. Func Plant Biol 37:1132-1142. doi:10.1071/FP09248

Miller R, Gleadow R, Cavagnaro T (2014) Age versus stage: does ontogeny modify the effect of phosphorus and arbuscular mycorrhizas on above- and below-ground defence in forage sorghum? Plant Cell Environ 37:929-942. doi:10.1111/pce.12209

Morin F, Fortin JA (1994) Apple rootstock response to vesiculararbuscular mycorrhizal fungi in a high phosphorus soil. J Am Soc Hortic Sci 119:578-583

Munkvold L, Kjoller R, Vestberg M, Rosendahl S, Jakobsen I (2004) High functional diversity within species of arbuscular mycorrhizal fungi. New Phytol 164:357-364. doi:10.1007/s00572-015-0631-x
Neeraj KS (2010) Cyamopsis tetragonoloba L Taub inoculated with arbuscular mycorrhiza and Pseudomonas fluorescens and treated with mustard oil cake overcome Macrophomina root-rot losses. Biol Fert Soils 46:237-245. doi:10.1007/s00374-009-0422-7

Neumann E, George E (2004) Does the presence of arbuscular mycorrhizal fungi influence growth and nutrient uptake of a wild-type tomato cultivar and a mycorrhiza-defective mutant, cultivated with roots sharing the same soil volume? New Phytol 166:601-609. doi:10. 1111/j.1469-8137.2005.01351.x

Nzanza B, Marais D, Soundy P (2012) Yield and nutrient content of tomato (Solanum lycopersicum L) as influenced by Trichoderma harzianum and Glomus mosseae inoculation. Sci Hortic 144:5559. doi:10.1016/j.scienta.2012.06.005

Okon I, Solomon MG, Osonubi O (2010) The effects of arbuscular mycorrhizal fungal inoculation and mulch of contrasting chemical composition on the yield of cassava under humid tropical conditions. Sci World J 10:505-511. doi:10.1100/tsw.2010.59

Ortas I (2003) Effect of selected mycorrhizal inoculation on phosphorus sustainability in sterile and non-sterile soils in the Harran Plain in South Anatolia. J Plant Nut 26:1-17. doi:10.1081/PLN-120016494

Ortas I (2010) Effect of mycorrhiza application on plant growth and nutrient uptake in cucumber production under field conditions. Sp J Agri Res 8:116-122

Ortas I (2012) The effect of mycorrhizal fungal inoculation on plant yield, nutrient uptake and inoculation effectiveness under long-term field conditions. Field Crop Res 125:35-48. doi:10.1016/j.fcr.2011.08.005

Ortas I, Ustuner O (2014) The effects of single species, dual species and indigenous mycorrhiza inoculation on citrus growth and nutrient uptake. Eur J Soil Biol 63:64-69. doi:10.1016/j.ejsobi.2014.05.007

Ortas I, Ortakçi D, Kaya Z, Çinar A, Önelge N (2002a) Mycorrhizal dependency of sour orange in relation to phosphorus and zinc nutrition. J Plant Nut 25:1263-1279. doi:10.1081/PLN-120004387

Ortas I, Ortakçi D, Kaya Z (2002b) Various mycorrhizal fungi propagated on different hosts have different effect on citrus growth and nutrient uptake. Soil Sci Plant Anal 33:259-272. doi:10.1081/CSS120002392

Ortas I, Sari N, Akpinar C, Yetisir H (2011) Screening mycorrhiza species for plant growth, $\mathrm{P}$ and $\mathrm{Zn}$ uptake in pepper seedling grown under greenhouse conditions. Sci Hortic 128:92-98. doi:10.1016/j.scienta. 2010.12.014

Pandey R, Singh B, Nair TVR (2005) Impact of arbuscular-mycorrhizal fungi on phosphorus efficiency of wheat, rye, and triticale. J Plant Nut 28:1867-1876. doi:10.1080/01904160500251381

Pellegrino E, Bedini S (2014b) Enhancing ecosystem services in sustainable agriculture: biofertilization and biofortification of chickpea (Cicer arietinum L) by arbuscular mycorrhizal fungi. Soil Biol Biochem 68:429-439. doi:10.1016/j.soilbio.2013.09.030

Rhodes LH, Gerdemann JW (1978) Influence of phosphorus nutrition on sulfur uptake by vesicular-arbuscular mycorrhizae of onion. Soil Biol Biochem 10:361-364. doi:10.1016/0038-0717(78)90058-5

Saxena J, Minaxi, Jha A, (2014) Impact of a phosphate solubilizing bacterium and an arbuscular mycorrhizal fungus (Glomus etunicatum) on growth, yield and p concentration in wheat plants. Clean Soil Air Water 42:1248-1252. doi: 10.17221/982/2014-PSE

Schroeder MS, Janos DP (2004) Phosphorus and intraspecific density alter plant responses to arbuscular mycorrhizas. Plant Soil 264: 335-348. doi:10.1023/B:PLSO.0000047765.28663.49

Shahabivand S, Maivan HZ, Goltapeh EM, Sharifi M, Aliloo AA (2012) The effects of root endophyte and arbuscular mycorrhizal fungi on growth and cadmium accumulation in wheat under cadmium toxicity. Plant Physiol Biochem 60:53-58. doi:10.1016/j.plaphy.2012.07.018

Sharma MP, Adholeya A (2000) Enhanced growth and productivity following inoculation with indigenous AM fungi in four varieties of onion \{Allium cepa L) in an Alfisol. Bio Agri Hort 18:1-14. doi:10. 1080/01448765.2000.9754860 
Sharma MP, Reddy UG, Adholeya A (2011) Response of arbuscular mycorrhizal fungi on wheat (Triticum aestivum L) grown conventionally and on beds in a sandy loam soil. I J Microb 51:384-389. doi:10.1007/s12088-011-0134-1

Sorensen JN, Larsen J, Jakobsen I (2008) Pre-inoculation with arbuscular mycorrhizal fungi increases early nutrient concentration and growth of field-grown leeks under high productivity conditions. Plant Soil 307:135-147. doi:10.1007/s11104-008-9591-7

Steinkellner S, Hage-Ahmed K, Garcia-Garrido JM, Illana A, Ocampo JA, Vierheilig H (2012) A comparison of wild-type, old and modern tomato cultivars in the interaction with the arbuscular mycorrhizal fungus Glomus mosseae and the tomato pathogen Fusarium oxysporum f. sp. Lycopersici. Mycorrhiza 22:189-194. doi:10. 1007/s00572-011-0393-z

Stewart LI, Hamel C, Hogue R, Moutoglis P (2005) Response of strawberry to inoculation with arbuscular mycorrhizal fungi under very high soil phosphorus conditions. Mycorrhiza 15:612-619. doi:10. 1007/s00572-005-0003-z

Stonor RN, Smith SE, Manjarrez M, Facelli E, Smith FA (2014) Mycorrhizal responses in wheat: shading decreases growth but does not lower the contribution of the fungal phosphate uptake pathway. Mycorrhiza 24:465-472. doi:10.1007/s00572-014-0556-9

Subramanian KS, Santhanakrishnan P, Balasubramanian P (2006) Responses of field grown tomato plants to arbuscular mycorrhizal fungal colonization under varying intensities of drought stress. Sci Hortic 107:245-253. doi:10.1016/j.scienta.2005.07.006

Subramanian KS, Tenshia V, Jayalakshmi K, Ramachandran V (2009) Biochemical changes and zinc fractions in arbuscular mycorrhizal fungus (Glomus intraradices) inoculated and uninoculated soils under differential zinc fertilization. Appl Soil Ecol 43:32-39. doi:10. 1016/j.apsoil.2009.05.009

Sudova R, Vosatka M (2007) Differences in the effects of three arbuscular mycorrhizal fungal strains on $\mathrm{P}$ and $\mathrm{Pb}$ accumulation by maize plants. Plant Soil 296:77-83. doi:10.1007/s11104-007-9291-8

Sylvia DM, Alagely AK, Chellemi DO, Demchenko LW (2001) Arbuscular mycorrhizal fungi influence tomato competition with bahiagrass. Biol Fert Soils 34:448-452. doi:10.1007/s00374-0010429-1

Talaat NV, Shawky BT (2014) Modulation of the ROS-scavenging system in salt-stressed wheat plants inoculated with arbuscular mycorrhizal fungi. J Plant Nut Soil Sci 177:199-207. doi:10.1002/jpln. 201200618

Tan Z, Hu Y, Lin Z (2012) Expression of NtPT5 is correlated with the degree of colonization in tobacco roots inoculated with Glomus etunicatum. Plant Mol Bio 30:885-893. doi:10.1007/s11105-011-0402-6

Tawaraya K, Hirose R, Wagatsuma T (2012) Inoculation of arbuscular mycorrhizal fungi can substantially reduce phosphate fertilizer application to Allium fistulosum $\mathrm{L}$ and achieve marketable yield under field condition. Biol Fert Soils 48:839-843. doi:10.1007/s00374012-0669-2

Tchabi A, Coyne D, Hountondji F, Lawouin L, Wiemken A, Oehl F (2010) Efficacy of indigenous arbuscular mycorrhizal fungi for promoting white yam (Dioscorea rotundata) growth in West Africa. Appl Soil Ecol 45:92-100. doi:10.1016/j.apsoil.2010.03.001

Torrisi V, Pattinson GS, Mcgee PA (1999) Localized elongation of roots of cotton follows establishment of arbuscular mycorrhizas. New Phytol 142:103-112. doi:10.1046/j.1469-8137.1999.00377.x

Urcoviche RC, Gazim ZC, Dragunski DC, Barcellos FG, Alberton O (2015) Plant growth and essential oil content of Mentha crispa inoculated with arbuscular mycorrhizal fungi under different levels of phosphorus. Ind Crops Prod 67:103-107. doi:10.1016/j.indcrop. 2015.01.016

Vaast P, Zasoski RJ, Bledsoe CS (1996) Effects of vesicular-arbuscular mycorrhizal inoculation at different soil $\mathrm{P}$ availabilities on growth and nutrient uptake of in vitro propagated coffee (Coffea arabica $\mathrm{L})$ plants. Mycorrhiza 6:493-497. doi:10.1007/s005720050153

Wang FY, Lin XG, Yin R (2007a) Effect of arbuscular mycorrhizal fungal inoculation on heavy metal accumulation of maize grown in a naturally contaminted soil International. J Phytoremediat 9:345-353. doi:10.1080/15226510701476214

Wang FY, Lin XG, Yin R (2007b) Inoculation with arbuscular mycorrhizal fungus Acaulospora mellea decreases $\mathrm{Cu}$ phytoextraction by maize from Cu-contaminated soil. Pedobiologia 51:99-109. doi: 10.1016/j.pedobi.2007.02.003

Wang S, Srivastava AK, Wu Q, Fokom R (2014) The effect of mycorrhizal inoculation on the rhizosphere properties of trifoliate orange (Poncirus trifoliata L Raf). Sci Hortic 170:137-142. doi:10.1016/j. scienta.2014.03.003

Watts-Williams SJ, Cavagnaro TR (2012) Arbuscular mycorrhizas modify tomato responses to soil zinc and phosphorus addition. Biol Fert Soils 48:285-294. doi:10.1007/s00374-011-0621-x

Watts-Williams SJ, Patti AF, Cavagnaro TR (2013) Arbuscular mycorrhizas are beneficial under both deficiënt and toxic soil zinc conditions. Plant Soil 371:299-312. doi:10.1007/s11104-013-1670-8

Wu Q, Zou Y, Huang Y (2013) The arbuscular mycorrhizal fungus Diversispora spurca ameliorates effects of waterlogging on growth, root system architecture and antioxidant enzyme activities of citrus seedlings. Fung Ecol 6:37-43. doi:10.1016/j.funeco.2012.09.002

Wu Q, Ni Q, Huang W (2014) Calcium and calmodulin involve in mycorrhizal and root development in trifoliate orange colonized by Rhizophagus intraradices. Not Bot Horti Agrobo 42:380-385. doi: 10.15835/nbha4229635

Wu Q, Lou YG, Li Y (2015a) Plant growth and tissue sucrose metabolism in the system of trifoliate orange and arbuscular mycorrhizal fungi. Sci Hortic 181:189-193. doi:10.1016/j.scienta.2014.11.006

Wu Q, Li Y, Zou Y, He X (2015b) Arbuscular mycorrhiza mediates glomalin-related soil protein production and soil enzyme activities in the rhizosphere of trifoliate orange grown under different $\mathrm{P}$ levels. Mycorrhiza 25:121-130. doi:10.1007/s00572-014-0594-3

Wu Q, Srivastava AK, Cao M, Wang J (2015c) Mycorrhizal function on soil aggregate stability in root zone and root-free hyphae zone of trifoliate orange. Arch Agr Soil Sci 61:813-825. doi:10.1080/ 03650340.2014 .952226

Xia Y, Chen B, Christie P, Smith FA, Wang YS, Li X (2007) Arsenic uptake by arbuscular mycorrhizal maize (Zea mays L) grown in an arsenic-contaminated soil with added phosphorus. J Environ Sci 19: 1245-1251. doi:10.1016/S1001-0742(07)60203-4

Xiao JX, Hu CY, Chen YY, Yang B, Hua J (2014) Effects of low magnesium and an arbuscular mycorrhizal fungus on the growth, magnesium distribution and photosynthesis of two citrus cultivars. Sci Hortic 177:14-20. doi:10.1016/j.scienta.2014.07.016

Yasmeen T, Hameed S, Tariq M, Ali S (2012) Significance of arbuscular mycorrhizal and bacterial symbionts in a tripartite association with Vigna radiate. Acta Physiol Plant 34:1519-1528. doi:10.1007/ s11738-012-0950-x

Zhang XH, Zhu YG, Chen BD, Lin AJ, Smith SE, Smith FA (2005) Arbuscular mycorrhizal fungi contribute to resistance of upland rice to combined metal contamination of soil. J Plant Nut 28:2065-2077. doi:10.1080/01904160500320871 